\title{
Editorial
}

\section{Morality and the Antarctic Treaty}

$\mathbf{P}$ olitics is the art of the possible and history suggests that morality has proved to be a handy tool to justify decisions and actions. But morality itself is a constantly changing construct. Religious wars were once virtuous but now are anathema to most people. Once the death penalty was a justified sentence and previously enslaving others was seen as good business but in the 21 st century it is apparently wrong in virtually all countries. So, given that morality is flexible and apparently largely linked to areas with human populations what can it have to do with Antarctica?

Although the Antarctic is normally considered a preserve for scientists, over recent decades a wider variety of academics have begun to see opportunities there. Whilst the international lawyers have been interested in the more arcane interpretations of legal understanding since before the Treaty was signed in 1959 it took considerably longer for some of the other areas of arts and social sciences to both recognise the potential and for those controlling the logistics to see their requests for access as legitimate.

Now we have a growing corpus internationally of artists and writers who have produced not only photographs, music and paintings but also poetry and plays, jewellery and fabrics, narratives and fiction in a range of languages. But so far, we have not had anyone address the morality of Antarctica head on. Yes, we have established ethical standards for the treatment of animals, for the conduct of research, for the protection of the environment. But what of the greater elements of morality that impinge on Article 4 of the Antarctic Treaty that deals with sovereignty claims?

The most recent approach has been the suggestion that there is a need to assess the morality of both the claims to Antarctic territory and the operation of the Antarctic Treaty. Surely there can be little doubt about membership of the Treaty since accession is open to any state party? But is it morally right that countries should be barred from making new laws for Antarctica if they are not committed to working on the continent and sharing their new knowledge? Is the Treaty itself simply a neo-colonial hangover from an earlier age that perpetuates the idea that all countries are not equal either in power or in importance?

A new research project based in Norway and involving academics from several countries (Australia, United Kingdom, Chile, Canada and Eire) is about to consider the ethical basis for the Treaty and its rules, as well as determining the morality of claiming an uninhabited land. The project entitled "Political Philosophy Looks to Antarctica: Sovereignty, Resource Rights and Legitimacy in the Antarctic Treaty System" will first look at what constitutes a fair distribution of the continent's natural resources - once they have determined what "fair" might mean. They will also consider if there are any moral reasons for the territorial claims and if the present system is simply a "rich man's club" where poor nations will forever be denied a say in its governance.

Whilst this promises to be an interesting academic exercise it will be all too easy for it to become detached from reality. Morality in international politics could be considered a loose arrangement of opportunistic decisions that suit the moment. What is interesting about Antarctica is that the decisions reached in 1959 have survived unchanged despite the growth in Treaty membership and a substantially altered geopolitical context. Perhaps the principles that we already have - collaboration, consensus, benefit sharing and tolerance - should be the starting point for any modern assessment of morality?

D.W.H. WALTON 